This is an Accepted Manuscript of an article
published by Taylor \& Francis in [Heat
transfer engineering] on 15 Mar 2018
available
https://doi.org/10.1080/01457632.2018.144229
0

Without prejudice to other rights expressly allowed by the copyright holders, this publication can be read, saved and printed for research, teaching and private study. Any other noncommercial and commercial uses are forbidden without the written permission of the copyright holders. 


\title{
The challenge to measure single-phase convective heat transfer coefficients in microchannels
}

\author{
Gian Luca Morini \\ Dipartimento di Ingegneria Industriale - Alma Mater Studiorum - Università di Bologna \\ Viale Risorgimento 2, 40136 Bologna (Italy)
}

Corresponding Author:

Prof. Ing. Gian Luca Morini, DIN Viale Risorgimento 2, I-40136 BOLOGNA (ITALY) tel. +390512093381 , fax.+390512093296

e-mail: gianluca.morini3@unibo.it 


\section{ABSTRACT}

The determination of local convective heat transfer coefficients in microfluidics is a very hard task. Due to the small dimensions of channels and walls, the use of conventional measurement techniques is only partially suitable in Microfluidics. For this reason, a strong effort has been made during the last decades in order to propose innovative techniques which use internal (to micro-devices) sensors of reduced dimensions and/or external conventional sensors. In this paper a review of the main experimental techniques proposed for the determination of the local near-wall fluid temperature, of the local wall temperature, of the local fluid bulk temperature will be given by putting in evidence for each technique positive and negative aspects as well as their actual limitations with the aim to stimulate and address the research on this topic in the next future. The problems and the limitations existing nowadays for the accurate measurements of the local thermal properties of a convective micro-flow demonstrates that for the analysis of micro-convection experimental data have to be always integrated by a numerical modeling of the observed system. 


\section{INTRODUCTION}

During the last twenty years the analysis of forced convection in micro-devices has attracted the interest of many researchers as demonstrated by the large number of works appeared in scientific journals linked to this topic as well as by the impressive number of patents involving convective aspects in microfluidics. In this period the comprehension of the heat transfer mechanisms in microfluidic devices has been dramatically increased, first of all as a consequence of the improved capability to make accurate measurements at micrometric scales [1-4]. In fact, the scientific and industrial interest on microfluidics has stimulated the development of new experimental techniques for the measurement of local fluid velocity, temperature, pressure, flow rates, concentrations and other measurable quantities.

However, the experimental determination of local convective heat transfer coefficients both for single phase and two phase flows in micro-devices has to be still considered an open question due to the problems linked to the monitoring of internal micro-flows. In this paper the discussion of the problems related to the measurement of convective heat transfer coefficients in micro-channels will be used in order to introduce a more general debate about the experimental characterization of microsystems.

A general conclusion of the studies conducted on micro-devices during the last two decades is that, due to their small dimensions, for the experimental characterization of these devices the researchers are called to select one of the following two approaches:

- To avoid the introduction of invasive sensors within the system; in this case the measured quantities are not sufficient to allow an accurate determination of the local convective heat transfer coefficients along the micro-channel and the behavior of the whole system must be generally inferred from an incomplete set of experimental data;

- To accept the introduction of miniaturized sensors within the system in order to collect more information about the microsystem; in this case the presence of these sensors can perturb the behavior of the system and the effects due to the sensors must be accounted for during the 
data post-processing in order to understand the real behavior of the system.

In many practical cases the researchers are forced to follow the first approach because the introduction of sensors inside the micro-device is not suitable; in these cases, only sensors placed externally to the system can be used in order to monitor the system (i.e. sensors placed at the inlet and at the outlet of a micro-channel and/or on the external surface of the device) and in this way only an overall characterization of the device performance can be obtained, with no chance to obtain local information inside the micro-device.

The second approach becomes suitable if specific micro-sensors can be integrated along the internal walls of a micro-device and/or, in case of presence of an optical access, if active or passive tracers can be added to the working fluid in order to obtain local information about the inner flow (i.e. fluorescent particles/molecules used for the reconstruction of the velocity and temperature field in a micro-channel).

Both in the first and in the second case it becomes crucial to be able to couple to the experimental analysis a numerical model of the whole microsystem with the aim to obtain from the numerical model:

- The completion of the information gap due to the limited number of available measured data (first approach) by using the experimental data as "boundary conditions" for the numerical runs;

- A complete investigation of the interactions between the sensors introduced within the micro-device and the system (second approach).

In this paper, it will be demonstrated that the analysis of forced convection in micro-channels usually needs a combined experimental/numerical approach, as evidenced by Morini and Yang [5] and, more recently, by Wang et al. [6]. This is partially due to the problems linked to the problems which afflict the measurement of the local fluid properties within the micro-systems. 
In the next sections, after a theoretical framing on forced convection in micro-devices, a review of the most promising techniques proposed in the last years for the analysis of the local and average convective heat transfer coefficients in micro-channels is presented. The presence of specific gaps in the experimental techniques proposed up to now for the analysis of micro-convection will be highlighted with the aim to stimulate and address the research on this topic in the next future.

\section{FORCED CONVECTION IN MICROCHANNELS}

Convective pressure-driven single phase fluid flows in micro-channels can be studied theoretically by determining the fluid velocity and temperature distribution using the mass, momentum and energy balance equations. If the continuum hypothesis is still valid for the working fluid within the microdevice, the classical formulation of the balance equations can be generally used $[4,5]$.

The convective heat transfer coefficients along a micro-channel are usually computed by means of the Nusselt number. As evidenced by Morini and Yang [5], for laminar flows in micro-channels the Nusselt number depends not only on the micro-channel geometry and on the imposed thermal boundary conditions (like in conventional channels) but also on a series of other dimensionless parameters, each one linked to a specific scaling effect (see Table 1). It has been demonstrated that the main scaling effects which have to be considered in the analysis of micro-convection are: (i) Entrance effects; (ii) Flow compressibility; (iii) Viscous dissipation; (iv) Wall-fluid conjugate heat transfer; (v) Fluid axial conduction; (vi) Surface roughness; (vii) Gas rarefaction; (ix) Electroosmotic effects. In addition to these effects, the influence of the fluid temperature dependent properties can be considered in some case important for the analysis of micro convection both for liquids and gases.

In Table 1 a specific dimensionless parameter has been associated to each scaling effect. A threshold value has been linked to these parameters in order to check if the single effect can be considered negligible during an experimental test. 
In micro-channels, special attention must be paid to conjugate effects due to the combined convection/conduction heat transfer between walls and fluid, to viscous dissipation effects both for liquids and gases, to flow compressibility effects for high pressure gas flows, to rarefaction effects for low pressure gas flows and electro-osmotic effects for polar liquid flows (i.e water) in presence of silicon walls.

The evaluation of the range of the expected values assumed by each dimensionless parameter reported in Table 1 before to start an experimental test ("a priori evaluation of scaling effects") is a useful tool in order to know the significance of each single scaling effect. In this way, an accurate interpretation of the experimental data can be obtained [5].

From an experimental point of view, the analysis of convective mechanisms in microchannels needs the capability to measure a series of local and global parameters like fluid velocity, temperature and mass flow rate. In fact, in order to estimate the local value of the convective heat transfer coefficients in a micro-channel, the measure of the local temperature difference between the fluid and the walls and of the local temperature gradients at the walls is needed, as indicated by the definition of the local Nusselt number at distance $x$ from the micro-channel inlet:

$$
N u_{x}=\frac{D_{h} q^{\prime \prime}{ }_{w, i, x}}{k_{f}\left(T_{w, i, x}-T_{b, x}\right)}=-\left.\frac{D_{h}}{\left(T_{w, i, x}-T_{b, x}\right)} \frac{\partial T}{\partial n}\right|_{w, i, x}
$$

where $D_{h}$ is the hydraulic diameter of the micro-channel, $n$ is the normal to the solid wall and $k_{f}$ is the fluid thermal conductivity.

The local values of the fluid bulk temperature $\left(T_{b, x}\right)$ and of the heat flux on the inner wall $\left(q{ }^{\prime \prime}{ }_{w, i, x}\right)$ are difficult to measure along a microchannel due to the small dimensions of the system (but this represents a challenge also for conventional tubes). Less problematic is the measurement of the local wall temperature $\left(T_{w, i, x}\right)$; this parameter can be measured by using high-precision miniaturized thermocouple probes, infra-red thermometry (IRT) or integrated resistance temperature detectors (RTD) [1]. On the contrary, the evaluation of the local fluid bulk temperature is a hard task; in fact, 
the bulk temperature is known only if both fluid velocity and temperature distributions are known simultaneously; in this case $T_{b, x}$ can be calculated as:

$$
T_{b, x}=\frac{\int_{\Omega} \rho u(x, y, z) c_{p} T(x, y, z) d y d z}{\Omega W \rho c_{p}}
$$

On the other hand, it is comparatively easier to gain from the experimental data the average value assumed by the Nusselt number along the micro-channel by using the following equation:

$$
N u_{a v}=\frac{D_{h} q^{\prime \prime}{ }_{w, i}}{k_{f} \Delta T_{l m}}
$$

where $k_{f}$ is calculated at the fluid average bulk temperature, $q{ }^{\prime}{ }_{w, i}$ is the average heat flux at the inner wall of the microtube calculated by means of an energy balance between the inlet and the outlet of the microtube:

$$
\mathrm{q}^{\prime \prime}{ }_{w, i}=\dot{m} c_{p f}\left(T_{b, \text { out }}-T_{b, \text { in }}\right) / \Gamma L
$$

$\Gamma$ is the perimeter of the cross section, $L$ is the channel length and $c_{p f}$ is the average value of the fluid specific heat.

In Eq.(3) $\Delta T_{l m}$ is the logarithmic-mean temperature difference between the wall and the fluid defined as usual as:

$$
\Delta T_{l m}=\frac{T_{b, \text { out }}-T_{b, \text { in }}}{\ln \left(\frac{T_{w, i, \text { in }}-T_{b, \text { in }}}{T_{w, i, \text { out }}-T_{b, \text { out }}}\right)}
$$

in which only temperature values measured at the inlet and at the outlet of the micro-device are involved.

By combining Eq.(3), Eq.(4) and Eq.(5) it is evident that $N u_{a v}$ can be obtained by using only temperature sensors placed at the ends of the micro-channels; this means that the average value of the Nusselt number can be always derived without to use local sensors placed within the microchannel. In this case conventional sensors can be used (i.e. pressure gauges, thermocouples, thermoresistances, mass flow meters, heat flux meters). 


\section{THE COMBINED EXPERIMENTAL/NUMERICAL APPROACH}

As evidenced in the previous section, in many cases the experimental determination of the local Nusselt number $\left(N u_{x}\right)$ is not possible in microchannels.

If the set of local measurements obtained along the microchannel is not complete (i.e. only extermal sensors are used), it becomes mandatory to integrate the experimental results with numerical results obtained by modeling the whole device; this approach is here called "hybrid approach" and it has been followed by many researcher in the past.

In the hybrid approach the numerical model uses the "incomplete set of measurements" as boundary conditions for the simulation of the whole system. In this way the hybrid approach allows the prediction of the local trends of velocity, pressure, temperature within the microdevice even if no direct measurements have been made inside the device. This procedure is exactly the same approach suggested by data assimilation techniques [7] developed for the analysis of big physical systems (i.e. meteorology). In big systems, in fact, it is impossible to measure all the local values of the desired physical quantities and there is the problem to reconstruct the trend of these quantities in regions in which no measurements are available. In Microfluidics the same problem there exists: even for relatively simple laboratory experiments (such as the classical analysis of a flow through a channel), information may be missing due to the use of a limited number of sensors (in general placed only at the ends of the microtubes), "shadowing", (i.e., obstructed view), proximity to the channel walls, fittings, opaque zones (heaters). Data assimilation suggests to combine observations of the state of a complex system with predictions from a numerical model of that same state. Inverse techniques [8] are an example of application of data assimilation methods. This approach has been suggested and followed by many researchers in Microfluidics in the past [9-13].

On the other hand, nowadays, in presence of an optical access to the micro-channel, innovative noninvasive measurement techniques (i.e. fluorescence techniques) able to give local information about fluid velocity and temperature distributions in micro-devices have been proposed. With these techniques it becomes theoretically possible to close the problem of the determination of the local 
convective heat transfer coefficients along a micro-channel by obtaining a complete set of local experimental data by means of the observation of passive or active tracers added to the working fluid. The effort to reduce the dimensions of these tracers enabled the use of these techniques for the investigation of smaller and smaller systems. However, the reduction of the tracer dimensions introduces additional problems due to the increase of the signal-to-noise ratio and to the presence of non-negligible interactions between the working fluid and the seeding which have to be computed by studying numerically these interactions. Once again, the integration between experimental and numerical methods becomes mandatory but, in this case, the numerical data are used for the postprocessing of the experimental data and not with the aim to complete the set of available experimental data. In this approach the numerical modeling is part of the experimental procedure; here this approach is called "integrated approach".

In the next section an overview of the main experimental techniques useful for the analysis of micro-convection will be given with the aim to highlight in which conditions the hybrid or the integrated approaches become mandatory for the analysis of forced convection in micro-systems. A series of examples will be shown in order to better explain the difference between these two approaches.

\section{VELOCITY AND TEMPERATURE MEASUREMENT IN MICROFLUIDICS}

\section{Fluid velocity and temperature measurement}

In presence of an optical window, for the determination of the local fluid velocity and temperature in a micro-channel by minimizing the flow disturbance a series of optical techniques have been proposed. These techniques are based on the observation of tracers dispersed within the working fluid. The seeding added to the working fluid must be small enough to follow fluid motion, large enough to be visible and homogeneously distributed in the working fluid. In addition, the introduction of tracers within the working fluid should not alter fluid/flow properties $[14,15]$.

Two kind of tracers can be added to the fluid: 
- Passive tracers: the particles are added to the working fluid with the aim to follow faithfully the flow;

- Active tracers: the particles follow the fluid and they are characterized by special properties which can be activated in order to measure the local value assumed by a physical quantity (i.e. concentration, shear stress or temperature).

The tracers are defined as "micrometric tracers" if characterized by an average diameter larger than $0.1 \mu \mathrm{m}$ (i.e. latex particles, smoke, liquid crystals, oil and water droplets) or "sub-micrometric or molecular tracers" if characterized by an average diameter lower than $0.1 \mu \mathrm{m}$ (i.e. acetone or biacethyl molecules)

\section{Passive tracers}

Passive tracers are generally used by velocimetry techniques; fluorescent micrometric polystyrene particles or oil droplets are generally used for the determination of the velocity field by using the displacement of groups of tracers in micro Particle Image Velocimetry ( $\mu$ PIV), the strikes of the fluorescent dye in Particle Striking Velocimetry (PSV) or the displacement of each single particle in Particle Tracking Velocimetry (PTV, APTV). On the contrary, molecular passive tracers are used in Molecular Tagging Velocimetry (MTV).

Micro Particle Image Velocimetry ( $\mu$ PIV) is the most widely used technique for local velocity measurements of a flow inside micro-channels (see Lindken et al. [15] and Lee and Kim [16]). The seeding particles, typically polystirene particles having diameters between 0.2 and $2 \mu \mathrm{m}$, are chosen with the same density of the working fluid in order to obtain a complete correspondence between the motion of the working fluid and the tracers without to introduce significant disturbance on the fluid motion. Due to the typical properties of the particles used as tracers (polystyrene particles), $\mu \mathrm{PIV}$ is generally indicated for the velocity determination of liquid flows in micro-channels; on the contrary, its application to gas flows is not an easy task because the seeding is not able to follow the 
gas flow due to the significant density difference existing between the gas and the tracers. In fact, up to now, only few works have used $\mu$ PIV for the analysis of gas flows in micro-channels $[17,18]$. In $\mu$ PIV the mean motion of a group of particles in a small detection area, called interrogation cell, is used in order to reconstruct the velocity field (Eulerian scheme). A series of images (at least two) is required in order to associate to each interrogation cell the corresponding velocity vector. In order to gain the information from the micrometric particles a magnification of the recorded images is required; usually, the sample under investigation is visualized by using an epi-fluorescent microscope in which a magnification lens is present along the light path. This entails a volumetric illumination of the flow. For this reason, in $\mu$ PIV not only the particles that are on the objective focal plane give an useful signal but also the particles that are within a fixed layer centered on the focal plane and characterized by a thickness, called depth of correlation (DOC), give back an additional signal used in the cross-correlation procedure.

Also Particle Tracking Velocimetry (PTV) techniques use passive fluorescent particles dispersed inside the working fluid in order to detect the motion of the flow $[19,20]$. However, in this case a Lagrangian approach is adopted: the displacement of each single particle is tracked, in all the field of view, from different images acquired with a constant time delay. Therefore, a velocity vector is associated to the single particle displacement. Simplified tracking methods can be used, even if the related uncertainties associated to the velocity measurements are higher compared to employment of the cross-correlation methods utilized by $\mu$ PIV technique, as indicated by Cierpka and Kähler [21]. However, the PTV technique introduces some advantages with respect to the $\mu$ PIV technique as underlined by Sato et al. [22], Cierpka and Kähler [21] and Cierpka et al. [23]. First of all, a lesser number of particles is required: this gives a drastic advantage in order to reduce the bright noise induced by particles out of focus inside the depth of correlation and this fact decreases the effects of bias errors. In addition, for flows in steady state conditions the spatial resolution can be increased with respect to $\mu$ PIV methods. In fact, through an acquisition of a higher number of 
images, the distance between velocity vectors can be reduced, where for $\mu$ PIV method this is not possible since the spatial resolution is determined by the size of the interrogation cell. In addition, since common $\mu$ PIV methods employ a time-averaged cross-correlation of acquired data, unsteady flows, such as pulsating flows, cannot be detected while through tracking methodologies this becomes possible [22]. In addition, as shown by Sato et al. [22], through spatially-averaged methods of PTV the bias errors induced by the Brownian motion of the particles can be eliminated also for velocity measurements with time resolution.

Recently, Cierpka et al. [24] have developed a PTV technique for the detection of the threedimensional velocity field of a flow inside a microchannel, in which the information given by outof-focus fluorescent passive particles is used in order to obtain the displacement of the particles along the direction perpendicular to the observation plane. This technique is called Astigmatism Particle Tracking Velocimetry (APTV) and it is simply realized by adding a cylindrical lens along the light path between the classical spherical lens of the microscope and the CCD or CMOS sensor for image acquisition (see Rossi and Kähler [25]). Three fundamental advantages can be obtained with the APTV method: first, this technique gives fundamental information about the threedimensional characteristics of the flow; second, it reduces sensibly the bias error induced by out-offocus particles and, third, the measurement of the three-dimensional velocity field is possible with the employment of a single camera.

About this last characteristic it is possible to highlight that the $3 \mathrm{D}$ velocity field in a microchannel can be also reconstructed through the stereoscopic $\mu \mathrm{PIV}$ technique proposed by Lindken et al. [26]. However, in this case two different cameras with a tilt angle in between are required in order to acquire simultaneously the images via a stereo lens with a magnification.

Molecular Tagging Velocimetry (MTV) can be defined as a whole field optical technique that relies on molecules that can be turned into long lifetime tracers upon excitation by photons of appropriate wavelength (see Koochesfahani and Nocera [27]). This technique uses passive 
molecular tracers for the velocity determination of liquid and gas flows in channels. It is possible to distinguish two cases:

(i) the molecules used as tracers (typically acetone or diacetyl) are added to the working fluid [27];

(ii) the molecules used as tracers are generated within the working fluid as product of a laser excitation of the molecules of the working fluid (i.e. NO molecules can be obtained by exciting a $\mathrm{N}_{2} \mathrm{O}$ flow [28]).

In the first case a pulsed laser is typically used to "tag" these molecules along a line or on a grid; molecules luminescence is then detected at two successive times within the lifetime of the fluorescence of the tracer. The analysis of the time evolution of the tagged line or grid allows the measurement of the Lagrangian displacement vector which provides the estimate of the fluid velocity vector ("read" procedure).

In the second case two pulsed lasers with two different wavelengths are used: the first one is used in order to generate the molecules employed as seeding and the second one to tag these molecules ("write and read" procedure).

The capability and the level of accuracy of MTV for the determination of the velocity field at micro scales ( $\mu \mathrm{MTV})$ has been demonstrated for liquid flows by Thompson and Maynes [29] and Maynes and Webb [30]. Its application to gaseous flows has been recently realized for internal microflows by Samouda et al. [31] by using one laser and by Yamaguchi et al. [32] by using two lasers.

As MTV technique uses molecular tracers instead of particles, it presents several advantages compared to $\mu \mathrm{PIV}$; for example, the repartition of the tracer is more homogeneous and the risk of adhesion of the seeding at the walls is more limited but the typical signal-to-noise ratio is generally lower. 
For gas microflows, in absence of oxygen, MTV measurements can be performed with a variety of organic phosphors. Some of the most popular tracers for gas flows are biacetyl and acetone. Nevertheless, oxygen completely quenches the green phosphorescence of biacetyl and acetone even if in small concentrations. The main consequence of this is that this technique cannot be used for oxygenated flows such as air.

Samouda et al. [31] and Yamaguchi et al. [32] have shown that it is possible to use $\mu$ MTV also in presence of rarefied gas microflows but for the lowest pressures $(<1000 \mathrm{~Pa})$, it becomes mandatory to improve the signal increasing the number $m$ of averaged images or the number $n$ of UV pulses per image with the aim to improve the signal-to-noise ratio [31].

\section{Active tracers}

Active tracers are needed for the determination of the temperature field within microchannels, like in the Laser Induced Fluorescence (LIF) techniques, Molecular Tagging Thermometry (MTT) and Thermochromic Liquid Crystals (TLC).

The common aspect of these technique is that they are based on the observation of tracers which are able to change their properties (i.e. fluorescence intensity, hue or color) if the local temperature varies. In the case of Laser Induced Fluorescence (LIF) technique, the fluid is typically seeded with a fluorescent dye (i.e. fluorescein or rhodamine B) that changes its fluorescence intensity as a function of the local temperature (Crimaldi [33]). The exciting light is delivered from a laser system but in some case an arc mercury lamp can be equally used (Ross et al. [34]). The main drawback of this method, is that the accuracy of this technique is strongly affected by the intensity and uniformity of the light excitation as well as by the concentration of the seeding. An improvement of the LIF technique is given by the dual-emission LIF method (DeLIF), also known as two-color or radiometric LIF method [35-38]. In the DeLIF method two different dyes are involved: one dye shows a temperature dependent behavior (i.e. rhodamine B, fluorescein, Kiton Red), while the second one is a temperature-insensitive dye (i.e. rhodamine 110, sulforhodamine 101) and it is used 
for the normalization of the signal given by the temperature-sensitive one. The sensitivity of DeLIF can be further improved by using two temperature-sensitive species with inverted temperature sensitivities. In this case the couple of tracers employed are Fluorescein and sulforhodamine B (Shafii et al. [39]) or fluorescein 27 and rhodamine B (Sutton et al. [40]).

Since in microfluidic applications is not possible to illuminate the flow with a thin laser sheet, the dye gives back a signal for all the depth of the illuminated volume. This means that with this technique the output signal is an integrated signal linked to the temperature distribution of the working fluid along all the depth of the illuminated volume. Experiments in which both the velocity and the temperature distribution of a liquid in motion were detected, are reported in the works of Someya et al. [37] and Vogt and Stephan [41].

Phosphorescent alcohol solutions are currently involved in Molecular Tagging Thermometry (MTT) technique with the aim to use molecular tracers for measuring simultaneously the fluid temperature and velocity distribution. The term "molecular tagging thermometry" was coined by Thomson and Maynes [29] in order to underline the similarity with the MTV technique for the velocity measurement. Differently from LIF techniques, MTT techniques rely on the phosphorescent emission instead of the fluorescent one. Since the phosphorescent emission lasts for longer time than fluorescence, only one kind of molecular dye have to be dispersed inside the working fluid in order to obtain both temperature and velocity measurements. However, up to now, the application of MTT to channels having hydraulic diameters lower than $1 \mathrm{~mm}$ is still an open question. Thomson and Maynes [29] used a phosphorescent dye dispersed in an aqueous solution for the measurements of the temperature and velocity of a laminar flow of water inside a channel with a diameter of $5 \mathrm{~mm}$. In order to obtain these measurements, a series of coupled images with a short time delay between them has been acquired after the laser excitation (UV laser) of the molecular dye. The temperature was measured from the first image by means of a previously performed calibration between the phosphorescence intensity and the temperature of the dye, while the velocity distribution was derived through the MTV method. With the adopted configuration the 
authors were able to measure the flow temperature between $23{ }^{\circ} \mathrm{C}$ and $53{ }^{\circ} \mathrm{C}$ with a declared uncertainty of $1 \mathrm{~K}$. Nevertheless, they concluded that by reducing the working temperature range, the resolution of this technique can be increased both from an increasing of the CCD camera offset and from an increase of the fluid temperature. Hu and Koochesfahani [42] underline that, due to the long life of phosphorescent emission, the temperature sensitivity of the MTT technique can be modified by changing the time delay between the excitation caused by the laser burst and the phosphorescent images acquisition. In this way the intensity change of the phosphorescence emission related to a temperature change of $1 \mathrm{~K}$ can become ten times higher than the temperature sensitivity of the fluorescence involved in LIF techniques.

Thermochromic liquid crystals (TLC) change the color of the reflected light as a function of their temperature and they are widely used as temperature sensors. Basically, the wavelength change of the reflected light depends on the inner structure of the TLCs which, in turn, is influenced from the TLC temperature. TLCs were usually produced either as microencapsulated beads used as fluid tracer or as an unsealed material used in thin film covers for surface temperature measurements. Only few works have shown the use of TLCs as suspended non-encapsulated particles in flows [43-45]. The main advantage of unsealed TLC particles, is that the colors reflected from them are more brighter compared to the ones reflected from the microencapsulated TLCs. This means that the determination of the fluid temperature can become more accurate with the only problem related to the minimum spatial resolution of this technique which is linked to the typical diameters of the non-encapsulated particles, larger than 10-13 $\mu \mathrm{m}$, and the resistance of these particles to the exposition to large shear rates.

For sake of completeness, other techniques based on optical interferometry, exploiting the temperature dependence of the refractive index of water (Easley et al. [46]), optical detection of the phase transition of polymer solutions (Seger-Sauli et al. [47], Kitamura et al. [48]) and spectroscopic methods, different from fluorescence, including nuclear magnetic resonance (Lacey et al. [49,50]), and Raman effect (Kim et al. [51]) have been proposed but their application is limited 
by many physical constraints and at the moment only in few specific cases these techniques have been successfully applied in microfluidics.

\section{Wall temperature}

The local inner wall temperature of a microchannel can be measured by using different techniques. One of the most popular method is the use of high-precision miniaturized thermocouple probes (TC) placed close to the inner wall [1]. These probes have a characteristic size comparable to that of the microchannel and they can suffer from poor spatial and temporal resolution, sometimes resulting highly intrusive for the micro-system. This aspect can be alleviated by placing these probes within the solid walls at a distance from the wall-fluid interface and assuming a onedimensional temperature field between the probe and the interface. This assumption must be verified because in presence of strong conjugate effects between solid walls and fluid the temperature difference between the probe and the inner wall becomes a function not only of the wall thermal conductivity and of the distance between probe and interface but of the fluid mass flow rate through the channel also. In addition, if their relative size is significant if compared to the channel wall, this kind of probe is able to give only an area averaged temperature measurement and not a local value of the wall temperature. If the goal is to obtain the wall temperature along a channel with a high spatial resolution, an array of sensors must be placed along the device [1]. In some cases a series of integrated resistance temperature detectors (RTD) are directly embedded to the channel surfaces in order to obtain the indication of the wall temperature along the channel; however, these probes disturb the flow, affect wall surface smoothness and chemistry and require additional (expensive) fabrication steps. A review of the main characteristics of RTD and micro TC used for the analysis of microfluidic systems can be found in [1]. In addition, a series of nonintrusive techniques such as Infra-Red Thermography (IRT) [52-54] and Thermochromic Liquid Crystals (TLC) have been employed [55-57]. 
These last two techniques are able to give an indication of the wall surface with a very high spatial resolution (of the order of microns) but a series of challenges are associated to these techniques which can strongly reduce their accuracy.

About the use of IRT, this technique enables the analysis of the temperature distribution on a surface by reading the emission of infra-red light from IR-opaque walls if one knows the value of the surface emissivity. The applicability of IRT at micrometric scales have been proved, among others, by Hetsroni et al. $[10,11]$ by measuring the surface temperature of a stainless steel capillary tube.

A very complete analysis of the different challenges linked to the use of infra-red thermography in microfluidics is due to Patil and Narayanan [52]. In this analysis the problem of the reduction of the background radiation addressed by Hetsroni et al. [10,11] is deeply discussed together with the problems related to the calibration, to the performances of the optical equipment, to the determination of the surface emissivity in order to minimize the uncertainty.

Thermochromic liquid crystal (TLC) can be used as an oily paint for the measurements of the wall temperature in encapsulated or un-encapsulated form. Typically, TLC are available on the market in encapsulated form [55] with dimensions down to 10-20 $\mu \mathrm{m}$ which limit the maximum spatial resolution of the temperature field. Nowadays, un-encapsulated TLC are also available like those used by Hohmann and Stephan [56] for the analysis of the wall temperature of a stainless steel foil with a dimension of $20 \mathrm{~mm}$. They demonstrated that un-encapsulated TLC can be successfully used for the temperature wall measurement on micro-surfaces by obtaining a temperature spatial resolution of $0.8 \mu \mathrm{m}$ with an uncertainty of the order of $0.5 \mathrm{~K}$. Similar results have been obtained by Muwanga and Hassan [57]. Kenning et al. [58] have highlighted that, due to the possible thermal lag between the liquid crystals and the wall surface, the response time of TLC must be always compared with the characteristic time of the observed system in order to obtain accurate information about the dynamic behavior of the surface. 


\section{Near-to-wall fluid temperature}

Patil and Narayanan [52] demonstrated that IRT can be applied not only for the determination of the wall temperature through microchannels with IR-opaque walls but also for the determination of the near-to-wall liquid temperature of an opaque fluid (water) flowing through a silicon microchannel with IR-transparent walls. They demonstrated that silicon microchannels can have a degree of IRtransparence that enables the direct visualization of the liquid temperature close to the inner wall by using IRT. They observed that a broadband anti-reflective coating in the wavelength range of 3-5 $\mu \mathrm{m}$ deposited on the imaged side of a silicon wafer can guarantee a total transmittance for Si in air of 0.97. As observed by Patil and Narayanan [52], the measured temperature of water by using IRT in presence of IR-transparent walls is representative of an average fluid temperature in the near-wall region on a depth of few microns.

In order to use the measured near-wall fluid temperature for a quantitative estimation of the convective heat transfer coefficient at the wall, an accurate evaluation of the value of this depth is needed. This info can be obtained only by solving numerically the complete radiation transfer equations for the fluid by considering absorption, emission and transmission of radiant heat and convection.

Recently Liu and Pan [59] used IRT in presence of IR-transparent walls for the determination of the near-wall fluid temperature of a single-phase and two-phase flow (ethanol) through a microchannel. They avoided to estimate the depth of the near-wall region in which the temperature signal was collected for the treatments of their rough data extracted by the radiometric images. In order to calibrate their near-wall temperature measurements, Liu and Pan [59] compared their rough measurements with the temperature measured by a micro thermocouple directly inserted inside the microchannel (by introducing significant perturbations on the observed system). The comparison was made with fluid flowing conditions. Based on the thermocouple temperature measurements, the authors correlated the temperature of the fluid measured with IR thermography in the near-wall region to the fluid bulk temperature by introducing a constant correction coefficient. However, this 
kind of calibration can be considered very rough and it cannot guarantee accurate results. Through the employment of this coefficient, the uncertainty on the measured local bulk fluid temperature were estimated by Liu and Pan [59] to be of the order of $7.8 \%$ but this value can be considered optimistic and values larger than $15-20 \%$ have to be reasonably considered.

Another technique for the measurement of the fluid temperature close to the wall is Evanescentwave Fluorescence Thermometry (EFT) proposed by Kim and Yoda [60]. In this case the near-wall fluid temperature is estimated by analyzing the fluorescent emissions of fluorophores in a water solution illuminated by evanescent waves. Such waves are generated by the total internal reflection of light incident upon a glass-water interface; they are due to the portion of the incident light transmitted into the lower refractive index medium (water). These evanescent waves propagate into water with an exponential decay from the interface. The length scale of this exponential decay is $O(100 \mathrm{~nm})$ for visible light incident upon a glass-water interface. In this region, by using the evanescent waves it becomes possible to stimulate fluorescence in tracers added to the working fluid.

For the application of this experimental technique, commercial TIRF oil-immersion lenses for fluorescence microscopy can be used. The laser light is reflected at the back focal plane of the microscope objective at a point away from its axis. This puts the excitation light beam at a nonzero incident angle with respect to the optical axis of the objective and generates an evanescent wave able to illuminate with the laser light just a small region of fluid close to the glass-water interface within a distance of 100-300 $\mathrm{nm}$. Within this small region close to the glass surface of the channel it is possible to apply LIF or DeLIF thermometry in order to measure the near-wall fluid temperature. Since evanescent waves have their maximum intensity at the interface it is important to select a fluorophore combination having a small amount of adsorption onto glass and channel walls in order to obtain a good reproducibility of fluorescence thermometry data. Kim and Yoda [60] observed that while fluoresceine has a negligible adsorption on PDMS and glass, sulforhodamine B evidences a non negligible adsorption onto glass and PDMS surfaces. For this reason, the combination of 
Fluorescein and sulforhodamine B, with their inverted temperature sensitivities, cannot be used in combination with glass and PDMS walls. Hsieh et al. [61] recently used a DeLIF technique combined with evanescent waves using rhodamine B (sensitive tracer) and rhodamine 110 (insensitive tracer) in a PDMS channel with a glass cover.

A method for temperature imaging based on the temperature dependence of the Near-Infra-Red (NIRT) absorption of water has been proposed by Kakuta et al. [62]. They demonstrated that by using the modification of the absorption coefficient of water in the wavelength range from $1300 \mathrm{~nm}$ to $2200 \mathrm{~nm}$ the near-wall water temperature can be measured in the range between $28-38^{\circ} \mathrm{C}$ with an estimated temperature resolution of $0.2 \mathrm{~K}$. However, this method can be applied only with water and/or acqueous solutions in which solute concentrations are low and the calibration of the system is a delicate point for this technique.

In Table 2 a list of the experimental techniques summarized in this paragraph is shown. For each method the typical tracers are reported. By observing Table 2 it is evident that the techniques available for the analysis of the convective behavior of inner gas microflows are scarce and the experimental determination of both velocity and temperature distribution in a gas can be still considered an open question. In addition, few techniques enable to measure the fluid temperature distribution across a microchannel (both for liquid and gases). For this reason, in many works appeared in literature in the past, only the near-wall fluid temperature or the wall temperature has been monitored.

The simultaneous reconstruction of the $2 \mathrm{D}$ velocity and temperature distributions in a microchannels can be obtained only by combining different techniques (i.e. APTV+TLC or MTV+MTT) during the same experiment, as proposed recently by Segura et al. [45]. Unfortunately, in many practical cases the combination of different techniques is not possible and for the determination of the velocity and temperature distribution the experiment must be repeated two times under the same conditions. 


\section{WHEN A COMBINED NUMERICAL/EXPERIMENTAL APPROACH IS NEEDED}

Now the reader has an overview of the main experimental techniques available for the analysis of micro-convection. In this section by means of a series of examples it is explained when a combined numerical/experimental analysis is mandatory for a detailed analysis of micro-convection on the basis of the adopted experimental techniques.

\section{Hybrid approach}

Hybrid approach must be used each time that the local fluid bulk temperature along the channel cannot be measured directly. This occurs when only external measurements are made on the microsystem and/or only the trend of the wall temperature and/or the near-wall fluid temperature is known.

As explained before, the measurement of the temperature distribution on the external surface of a micro-channel (by using TC, RTD, IRT, TLC) or, in presence of an optical access, the measurement of the fluid near-wall temperature (by IRT, EFT, NIRT) is usually easier than the simultaneous measurement of the local 2D velocity and temperature field (by MTV+MTT for gas and liquid flows or APTV+TLC for liquid flows), as required for the local evaluation of the fluid bulk temperature (see Eq.(2)).

For this reason in many experimental works appeared in literature and devoted to the determination of convective heat transfer coefficients in micro-channels, the local value of the fluid bulk temperature along the channel was not measured directly [57,63-67]. When the local fluid bulk temperature along the channel is unknown, the set of measurements is not self-consistent and an exact evaluation of the convective heat transfer coefficients along the microchannel is not possible without to introduce a series of additional hypotheses on the thermal behavior of the system. In many cases, these hypotheses are borrowed by similar convective problems solved for conventional channels, neglecting the role played by the scaling effects when the dimensions of the channels decrease. More important, only in few cases these hypotheses are verified numerically. In these 
cases, the authors have implicitly coupled a numerical analysis to their experimental data (hybrid approach).

As an example, Muwanga and Hassan [57] evaluated the axial trend of the local Nusselt number along a microchannel by measuring: (i) the water mass flow rate $(\dot{m})$, (ii) the water bulk temperature at the entrance $\left(\mathrm{T}_{\mathrm{b}, \text { in }}\right)$ and at the outlet $\left(\mathrm{T}_{\mathrm{b}, \mathrm{out}}\right)$ of a fiberglass microchannel with a polycarbonate cover; (iii) the temperature distribution of the external surface of the channel $\left(\mathrm{T}_{\mathrm{w}, \mathrm{e}, \mathrm{x}}\right)$ by using an un-encapsulated TLC paint.

The authors calculated the local convective heat transfer coefficients along the channel by combining Eq.(1) with Eq.(4) under the assumptions that: (i) the wall heat flux on the inner surface of the channel is uniform along the axial direction $(x)$ of the channel; (ii) the wall temperature measured on the external side is equal to the wall temperature measured on the inner side:

$$
q^{\prime \prime, i}=q^{\prime \prime, i, x}, \quad T_{w, i, x}=T_{w, e x, x}
$$

If Eq.(6) holds, the local fluid bulk temperature along the channel can be calculated as follows:

$$
T_{b, x}=T_{b, i n}+\frac{q_{w, i}^{\prime \prime} \Gamma}{\dot{m} c_{p}} x
$$

which means that the fluid bulk temperature varies linearly between the inlet and the outlet values.

Once the local fluid bulk temperature is known, the local heat transfer coefficient and the local Nusselt number (by using Eq.(1)) can be calculated:

$$
h_{x}=\frac{q^{\prime \prime}{ }_{w, i, x}}{T_{w, i, x}-T_{b, x}}
$$

It is clear that this approach gives accurate results only if Eq.(6) and Eq.(7) hold. For this reason, for each experimental run these assumptions must be verified numerically by a CFD simulation of the whole system. The use of Eq.(6) and Eq.(7) without any verification was the origin of many nonphysical results appeared in literature in the past (see [63-66,5]).

In fact, in presence of strong conjugate effects $(M>0.01$, see Table 1) and/or in presence of strong entrance effects $(\mathrm{Gz}>10)$ and/or in presence of strong viscous dissipation $(\mathrm{Br}>0.005)$ the heat flux 
along the inner channel wall is no more uniform and the axial trend of the bulk temperature becomes strongly non-linear between the inlet and the outlet. As consequence, before to decide the more appropriate data reduction procedure in order to obtain from the experimental data the convective heat transfer coefficients, an a priori analysis of the main scaling effects is mandatory. In other words, in this case the appropriate data reduction procedure must be selected once a CFD simulation of the whole system is conducted and the main scaling effects are individuated. Without this analysis the evaluation of the Nusselt number can be completely wrong.

\section{Integrated approach}

The integrated approach is generally needed when the adopted experimental technique uses molecular tracers, like in MTV and MTT.

A relevant problem of the MTV technique applied to gaseous flows is the diffusion of the molecular dyes inside the gas, especially when the gaseous flow becomes more and more rarefied (Frezzotti et al. [68]). It is possible to demonstrate that, in order to extract the real value of the local velocity using MTV, the molecular diffusion of tracers inside the gas flow must be correctly taken into account. For the analysis of the particle diffusion within the gas flow Frezzotti et al. [68] executed a Monte Carlo direct simulation (DSMC) of the flow of the mixing (molecular tracer + working fluid). Either the free motion of the molecules than the collision between them were taken into account in the simulation. In this way it becomes possible to link the displacement of the molecular dye $\mathrm{s}_{\mathrm{x}}(\mathrm{y}, \mathrm{t})$ along the streamwise direction ( $x$ direction) to the gas velocity by using the following expression:

$$
\frac{\partial s_{x}(y, t)}{\partial t}=u_{x}(y)+D_{12} \frac{\partial^{2} s_{x}(y, t)}{\partial y^{2}}
$$

where $u_{x}(y)$ is the steady, fully developed velocity distribution of the gas far from the boundaries and $D_{12}$ is the diffusion coefficient of the dye molecules in the carrying gas. 
Since the use of molecular tracers within the working fluid can introduce non-negligible diffusion effects, Eq.(9) highlights that the seeding diffusion must be correctly modeled in order to be able to extract from the experimental data the real values of the local velocity. In other words, in MTV the experimental data must be always coupled to a numerical modeling of the diffusion phenomena of the mixing (molecular tracer + working fluid) in order to be able to obtain the velocity field in a gas flow, as demonstrated by Si Hadj Mohand [69]. In this case the numerical analysis of diffusion is integrated within the experimental technique because it allows the correct extraction of the velocity values from the measurements.

The integrated approach is also needed for a correct interpretation of the near-wall temperature obtained by EFT or IRT in presence of IR-transparent covers.

\section{Self-consistent data}

Only in very few cases it is theoretically possible to obtain a complete set of experimental data for the accurate determination of the local convective heat transfer coefficients along a microchannel. In these cases, the experimental data are self-consistent and no additional numerical data are needed.

The convective flow can be locally analyzed in detail by determining simultaneously velocity and temperature field in the micro-channel in two cases: (i) when APTV is coupled with TLC, as suggested by Segura et al. [45], or (ii) when the micro PIV technique is coupled with LIF technique (only for liquid flows), as proposed by Hishida et al. [70].

The test rig lay-out adopted by Segura et al. [45] is shown in Figure 1; water with addiction of un-encapsulated TLC particles (Hallcrest, UNR20C5W) is introduced by means of a syringe pump (5) in a rectangular copper microchannel $(200 \times 250 \mu \mathrm{m})(1)$ sealed with a glass and having three sides heated by means of a Peltier cell (2-3-4) able to vary the heat flux along the channel. A white light (11) is used in order to illuminate the TLC particles by means of an inverted microscope (7), its objective lens (8) and filters (linear polarizer (9) and achromatic quarter wave plate(10)) able to 
produce circularly polarized light. The light reflected by the TLC particles is collected by the microscope and sent to a RGB color camera (6). In this way it is possible to link a specific color to each TLC particle.

With this apparatus it is possible to obtain a reconstruction of the $2 \mathrm{D}$ velocity profile of water inside the microchannel by means of APTV applied to the TLC particles and, simultaneously, to use the color of TLC particles in order to obtain the 2D temperature distribution in the water flow.

A typical result of the simultaneous measurement of velocity and temperature obtained by using APTV and TLC is shown in Figure 2 in which the color of each point corresponds to the local fluid temperature. It is evident that the $2 \mathrm{D}$ velocity profile reproduces the laminar Poiseuille profile $(\operatorname{Re}=0.04)$ for rectangular ducts. The obtained velocity uncertainty was $\pm 5 \mu \mathrm{m} / \mathrm{s}(2 \%$ with respect to the maximum velocity) for the in-plane velocity and $\pm 29 \mu \mathrm{m} / \mathrm{s}(11.7 \%$ with respect to the maximum velocity) for the out-of-plane velocity [45]. The temperature measurement shows a uniform temperature field with an average temperature of $25.2{ }^{\circ} \mathrm{C}$. The estimated temperature uncertainty is equal to $\pm 0.5 \mathrm{~K}$ over a temperature response range of about $7.5 \mathrm{~K}$ [45].

It is important to highlight that the uncertainties which afflict the experimental data obtained by coupling APTV and TLC are higher with respect to those obtained when thermometry via TLC particles and velocimetry via APTV are performed separately. In fact, as stated by Segura et al. [45], when APTV method is applied to particles with lower brightness and a camera with low sensitivity is used, like in this case, higher uncertainties in terms of detection of particles position are expected. A more powerful illumination system and a more sensitive camera gives also advantages in terms of temperature detection: brighter particles coupled with an acquisition system with higher accuracy enable a more robust and precise calibration and consequently temperature measurements with lower uncertainties.

In this way the local bulk temperature $\left(T_{b, x}\right)$ can be measured along the channel; if the wall temperature is known in a discrete number of points along the axial direction by means of a series of thermocouples (TC) placed within the solid walls of the microchannels $\left(\mathrm{T}_{\mathrm{w}, \mathrm{i}, \mathrm{x}}\right)$ and in the same 
locations the local heat flux is measured close to the inner wall $\left(\mathrm{q},{ }^{\prime}{ }_{\mathrm{w}, \mathrm{i}, \mathrm{x}}\right)$, the value of the local heat transfer coefficient can be obtained without to use numerical data. This is the only case in which hybrid approaches or integrated approaches can be avoided for the analysis of micro-convection. Unfortunately, up to now a simultaneous measurement of velocity and temperature in a microchannel by using APTV+TLC is possible only for liquids and for channels larger than $200 \mu \mathrm{m}$ due to the typical size of the TLC particles (larger than 10-20 $\mu \mathrm{m}$ ). In addition, as evidenced by Puccetti et al. [43], un-encapsulated TLC particles, recommended for this kind of application due to their brilliant colors if compared with encapsulated TLC's, are destroyed if the local shear rate in the fluid overcomes a critical value which depends on the TLC bulk material considered. This fact limits the maximum Reynolds number that can be analyzed with this combined technique at $\operatorname{Re}<10$. In fact, when the shear rate increases some TLC particles start to collapse releasing their material. This phenomena is shown in Figure 3 where broken particles are evidenced: the difference between an intact and a broken particle is clearly shown by comparing the pattern of the particle marked by a circle in Figure 3a and 3b.

Nowaday, the intensity of the proper light sources and the weak sensitivity of RGB color cameras limit the employment of the TLC particles only to flows with low velocity, as indicated by Segura et al. $[44,45]$. Nevertheless, the relative simplicity of the required experimental apparatus, coupled with the possibility to simultaneously perform three-dimensional velocity measurements using a single camera by means of the APTV method, makes TLCs thermography really interesting and its development could bring it to become the principal technique for local temperature measurements in microchannels at low Reynolds numbers. However, at the moment, the combined application of APTV and TLC is possible only in few specific cases (low Reynolds numbers, presence of optical access, water as working fluid) and its generalization is far to be reached. 


\section{CONCLUSIONS}

The review of the most promising experimental techniques which can be used for the analysis of forced convection in microchannels puts in evidence that in many practical cases it is very difficult to measure all the needed quantities for an accurate estimation of the local convective heat transfer coefficients. In addition, in some case the interactions between the sensors and the observed system cannot be ignored. In order to overcome these problems, in Microfluidics it becomes mandatory to combine numerical simulations and experimental measurements with two distinct approaches:

- In presence of an incomplete set of experimental data, numerical simulations are used in order to fill the information gap: this approach is defined "hybrid approach".

- when the extraction of accurate values from the measurements needs to take into account the interactions between the sensors and the whole system, numerical simulations can help to quantify these interactions: in this case the numerical simulations are integrated to the experimental technique and the approach is defined "integrated approach".

A series of examples are shown in this paper in order to clarify in which cases these two approaches are followed on the basis of the experimental data available. From this analysis it is evident that:

- an accurate measurement of the local velocity and temperature of liquids within a microchannel is possible only if an optical access is present; without an optical access inverse methods coupled to contactless experimental techniques (IRT) enable to obtain information about the distribution of the local convective heat transfer coefficients along the microchannel but a series of problems (i.e. the control of the background radiant contribution) can increase the expected experimental uncertainty linked to the measured convective heat transfer coefficients up to $10-25 \%$.

- For gas flows through microchannels an accurate evaluation of the local value of velocity and temperature can be obtained only by using molecular tracers (MTV, MTT) but, until 
now, the use of these techniques for channels having dimensions lower than $0.5 \mathrm{~mm}$ and for dilute gases can be still considered an open problem. In addition, for gas flows $\mu$ PIV and PTV cannot be used.

- Un-encapsulated small liquid crystal particles added to a working fluid for the determination of the temperature field is a very promising technique because it can be coupled with the simultaneous evaluation of velocity (i.e. by using TLC as seeding with APTV). The main limits of unsealed TLC are their dimensions (larger than $10 \mu \mathrm{m}$ ) and their behavior in presence of large values of shear rate. At the moment, unsealed TLC can be used only in combination with liquid flows (i.e. water) and for low Reynolds numbers $(\operatorname{Re}<10)$. However, a new generation of TLC particles with reduced dimensions, able to resist to higher shear rates and able to reflect more light, are needed in order to improve this technique.

Even if many efforts have been addressed in the past to obtain new methods for the measurement of the wall surface temperature in microchannels, of the bulk fluid temperature as well as of the local temperature gradients close to the heated walls of a channel, the integration between numerical models and experimental measurements appears to be unavoidable when the dimensions of the observed physical system are reduced with respect to conventional systems. This aspect highlights how the observation of micro/nano-devices and big physical systems, like atmosphere, is a source of shared problems.

\section{ACKNOWLEDGMENTS}

This work has been founded through the H2020 MIGRATE project (grant agreement No. 643095). The support is gratefully acknowledged. 


\section{NOMENCLATURE}

APTV Astigmatic Particle Tracking Velocimetry

$\mathrm{Br} \quad$ Brinkman number

$c_{p} \quad$ specific heat capacity at constant pressure

$[\mathrm{J} /(\mathrm{kgK})]$

$\mathrm{c}_{\mathrm{v}} \quad$ specific heat capacity at constant volume

$[\mathrm{J} /(\mathrm{kgK})]$

$\mathrm{D}_{12}$ diffusion coefficient (dyes in the carrying gas) $\quad\left[\mathrm{m}^{2} / \mathrm{s}\right]$

$\mathrm{D}_{\mathrm{e}} \quad$ Dimensionless Debye length

d diameter

[m]

$\mathrm{D}_{\mathrm{h}} \quad$ inner hydraulic diameter

[m]

DeLIF Dual-emission Laser Induced Fluorescence

e electron charge

[C]

EFT Evanescent-wave Fluorescence Thermometry

$\mathrm{Gz} \quad$ Graetz number

h convective heat transfer coefficient

$\left[\mathrm{W} /\left(\mathrm{m}^{2} \mathrm{~K}\right)\right]$

$\mathrm{k}$ thermal conductivity

$[\mathrm{W} /(\mathrm{mK})]$

Kn Knudsen number

IRT Infra-Red Thermometry

L microtube length

[m]

LIF Laser Induced Fluorescence

$\dot{m} \quad$ mass flow rate

$[\mathrm{kg} / \mathrm{s}]$

M Conduction number

Ma Mach number

MTT Molecular Tagging Thermometry

$\mathrm{n}_{0} \quad$ average ion concentration

[M]

NIRT Near-Infra-Red Thermometry 
$\mathrm{Nu} \quad$ Nusselt number

p pressure

$[\mathrm{Pa}]$

Pe Peclet number

PIV Particle Image Velocimetry

Pr Prandlt number

PTV Particle Tracking Velocimetry

q" heat flux

$\left[\mathrm{W} / \mathrm{m}^{2}\right]$

R specific gas constant

$[\mathrm{J} / \mathrm{kgK}]$

Re Reynolds number

s displacement

[m]

t time

$[\mathrm{s}]$

T gas temperature

$[\mathrm{K}]$

TLC Thermochromic Liquid Crystal

u velocity

$[\mathrm{m} / \mathrm{s}]$

W average velocity

$[\mathrm{m} / \mathrm{s}]$

$\mathrm{Z} \quad$ ion valence

$\mathrm{x}, \mathrm{y}, \mathrm{z}$ cartesian coordinate

[m]

Greek symbols

$\varepsilon \quad$ electric permittivity

$\kappa_{\mathrm{b}} \quad$ Boltzmann's constant

$[\mathrm{J} / \mathrm{K}]$

$\zeta \quad$ gas mean free path

[V]

$\Gamma \quad$ channel perimeter

[m]

$\rho \quad$ gas density

$\left[\mathrm{kg} / \mathrm{m}^{3}\right]$

$\Omega \quad$ cross section area

$\left[\mathrm{m}^{2}\right]$ 


$\begin{array}{ll}\text { Subscripts } & \text { average } \\ \text { b } & \text { bulk } \\ \text { ex } & \text { external } \\ \text { f } & \text { fluid } \\ \text { i } & \text { inner } \\ \text { in } & \text { inlet } \\ \text { lm } & \text { logarithmic mean } \\ \text { out } & \text { exit } \\ \text { tot } & \text { total (channel }+ \text { solid walls) } \\ \text { w } & \text { wall } \\ x & \text { local }\end{array}$

\section{REFERENCES}

[1] Morini, G.L., Yang, Y., Chalabi H., Lorenzini, M., A Critical review of the measurement techniques for the analysis of gas microflows through microchannels, Exp. Thermal and Fluid Science, vol. 35, n. 6, pp. 849-865, 2011.

[2] Colin, S., Gas microflows in the slip flow regime: a critical review on convective heat transfer. ASME J. Heat Transfer, vol. 134, n. 2, paper 020908, pp.1-13, 2012.

[3] Kandlikar, S.G., Colin, S., Peles, Y., Garimella, S., Pease, R.F., Brandner, J.J., Heat Transfer in Microchannels - 2012 Status and Research Needs, ASME J. Heat Transfer, vol. 135, paper 091001, pp. 1-18, 2013.

[4] Morini, G.L, Scaling Effects for Liquid Flows in Microchannels, Heat Transfer Engineering, vol. 27 , n. 4 , pp. 64-73, 2006. 
[5] Morini, G.L., Yang, Y., Guidelines for the analysis of single-phase forced convection in microchannels, ASME J. Heat Transfer, vol. 135, paper 101004, pp. 1-10, 2013.

[6] Wang, Y., Nayebzadeh, A., Yu, X., Shin, J.H., Peles, Y., Local heat transfer in a microchannel with a pin fin - experimental issues and methods to mitigate, Int. J. Heat Mass Transfer, vol. 106, pp. 1191-1204, 2017.

[7] Lahos, W., Khattatov, B., Menard, R., Data Assimilation - Making Sense of Observations, Springer-Verlag, Heidelberg, 2010.

[8] Beck, J.V., Balckwell, B., St.Clair Jr., C.R., Inverse Heat Conduction - Ill Posed Problems, John Wiley \& Sons Inc., New York, 1985.

[9] Pradere, C., Joanicot, M., Batsale, J.C., Tiutain, J., Gourdon, C., Processing of temperature field in chemical microreactors with infrared thermography, QIRT Journal, vol. 3, pp. 117-135, 2006.

[10] Hetsroni, G., Gurevich, M., Mosyak, A., Rozenblit, R., Surface temperature measurement of a heated capillary tube by means of an infrared technique. Meas. Sci. Technol., vol. 14, n. 6, pp. 807-814, 2003.

[11] Hetsroni, G., Mosyak, A., Pogrebnyak, E., Rozenblit, R., Infrared temperature measurements in micro-channels and micro-fluid systems. Int. J. Thermal Science, vol. 50, n.6, pp. 853-868, 2011.

[12] Mollmann, K.P., Lutz, N., Vollmer, M., Thermography of microsystems, Information Proceeding, ITC, vol. 104 A, pp. 7-27, 2004.

[13] Liu, T.-L., Pan, C., Infrared thermography measurement of two-phase boiling flow heat transfer in a microchannel. App. Therm. Eng., vol. 94, pp. 568-578, 2016.

[14] Sinton, D., Microscale flow visualization, Microfluid. Nanofluid., vol. 1, n. 1, pp. 2-21, 2004. 
[15] Lindken, R., Rossi, M., Große, S., Westerweel, J., Micro-Particle image Velocimetry ( $\mu$ PIV): Recent developments, applications, and guidelines, Lab. Chip, vol. 9, pp. 2551-2567, 2009.

[16] Lee, S. J. and Kim, S., Advanced particle-based velocimetry techniques for microscale flows. Microfluid and Nanofluid, vol. 6, pp. 577-588, 2009.

[17] Yoon, S.J., Ross, J.W., Mench, M.M., Sharp, K.V., Gas-phase particle image velocimetry for application to the design of fuel cell reactant flow channel, J. of Power Sciences, vol. 160, pp. 1017-1025, 2006.

[18] Sugii, Y., Okamoto, K., Velocity measurement of gas flow using micro PIV techniquein polymer electrolyte fuel cell, Proc. of the $4^{\text {th }}$ Int. Conf. on Nanochannels, Microchannels and Minichannels (ICNMM2006), paper 96216, pp.1-8, June 19-21, Limerick (IL), 2006.

[19] Devasenathipathy, S., Santiago, J.G., Takehara, K., Particle tracking techniques for electrokinetic microchannel flows, Anal. Chem., vol. 74, pp. 3704-3713, 2002.

[20] Devasenathipathy, S., Santiago, J.G., Wereley, S.T., Meinhart, C.D., Takehara, K., Particle imaging techniques for microfabricated fluidic systems, Exp. in Fluids, vol. 34, n. 4, pp. 504514,2003

[21] Cierpka, C., Kähler, C.J., Particle imaging techniques for volumetric three-component (3D3C) velocity measurements in microfluidics. J. of Visualization, vol. 15, pp. 1-31, 2012.

[22] Sato, Y., Inaba, S., Hishida, K., Maeda, M., Spatially averaged time-resolved particle-tracking velocimetry in microspace considering Brownian motion of submicron fluorescent particles. Exp. in Fluids, vol. 35, pp. 167-177, 2003.

[23] Cierpka, C., Segura, R., Hain, R., Kähler, C.J., A comparative analysis of the uncertainty of astigmatism- $\mu$ PTV, stereo- $\mu$ PIV, and $\mu$ PIV. Exp. in Fluids, vol. 52, pp. 605-6015, 2012. 
[24] Cierpka, C., Segura, R., Hain, R., Kähler, C.J., A simple single camera 3C3D velocity measurement technique without errors due to depth of correlation and spatial averaging for microfluidics. Meas. Sci. Technol., vol. 21, paper 045401, pp.1-13, 2010.

[25] Rossi, M., Kähler, C.J., Optimization of astigmatic particle tracking velocimeters. Exp. in Fluids, vol. 55, paper 1809, pp. 1-13, 2014.

[26] Lindken, R., Westerweel, J., Wieneke, B., Stereoscopic micro particle image velocimetry. Exp. in Fluids, vol. 41, pp. 161-171, 2006.

[27] Koochesfahani, M.M., Nocera, D.G., Molecular Tagging Velocimetry, in Handbook of experimental fluid dynamics, eds. C. Tropea, A.L. Yarin, J.F. Foss, pp. 362-382, SpringerVerlag, Heidelberg, 2007.

[28] ElBaz, A. M., Pitz, R.W., N2O molecular tagging velocimetry, Applied Physics B, vol. 106, n. 4, pp. 961-969, 2012.

[29] Thomson, S., Maynes, D., Spatially resolved temperature measurements in a liquid using laser induced phosphorescence. ASME. J. Fluids Eng., vol. 123, n. 2, pp. 293-302, 2001.

[30] Maynes, D., Webb, R.A., Velocity profile characterization in sub-millimeter diameter tubes using molecular tagging velocimetry. Exp. in Fluids, vol. 32, n. 1, pp. 3-15, 2002.

[31] Samouda, F., Colin, S., Barrot, C., Baldas, L., Brandner, J.J., Micro molecular tagging velocimetry for analysis of gas flows in mini and micro systems. Microsys. Technol., vol. 21, n. 3, pp. 527-537, 2015.

[32] Yamaguchi, H., Hayashida, K., Ishiguro, Y., Takamori, K., Matsuda, Y., Niimi, T., Micromolecular tagging velocimetry for internal gaseous flow. Microfluid. Nanofluid., vol. 20, n. 32, pp. 1-10, 2016.

[33] Crimaldi, J. P., Planar laser induced fluorescence in aqueous flows. Exp. in Fluids, vol. 44, pp. 851-863, 2008. 
[34] Ross, D., Gaitan, M., Locascio, L.E., Temperature measurement in microfluidic systems using a temperature dependent fluorescent dye, Anal. Chem., vol. 73, n. 17, pp. 4117-4123, 2001.

[35] Coppeta, J., Rogers, C., Dual emission laser induced fluorescence for direct planar scalar behavior measurements, Exp. in Fluids, vol. 25, pp. 1-15, 1998.

[36] Sakakibara, J., Adrian, R.J., Whole field measurement of temperature in water using two-color laser induced fluorescence, Exp. in Fluids, vol. 26, pp. 7-15, 1999.

[37] Someya, S., Bando, S., Song, Y., Chen, B., Nishio, M., DeLIF measurement of ph distribution around dissolving $\mathrm{CO} 2$ droplet in high pressure vessel, Int. J. Heat Mass Transfer, vol. 48, pp. 2508-2515, 2005.

[38] Natrajan, V.K., Christensen, K.T., Two-color laser-induced fluorescent thermometry for microfluidic systems, Meas. Sci. Technol., vol. 20, paper 015401, pp. 1-11, 2009.

[39] Shafii, M.B., Lum, C.L., Koochesfahani, M.M., In-situ LIF temperature measurements in aqueous ammonium chloride solutions during uni-directional solidification, Exp. in Fluids, vol. 48, pp. 651-662, 2009.

[40] Sutton, J.A., Fisher, B.T., Fleming, J.W., A laser induced fluorescence measurement for acqueous fluid flows with improve temperature sensitivity, Exp. in Fluids, vol. 45, pp. 869-881, 2008.

[41] Vogt, J., Stephan, P., Using microencapsulated fluorescent dyes for simultaneous measurement of temperature and velocity fields. Meas. Sci. Technol., vol. 23, paper 105306, pp. 1-12, 2012.

[42] Hu, H., Koochesfahani, M.M., Molecular tagging velocimetry and thermometry and its application to the wake of a heated circular cylinder. Meas. Sci. Technol., vol. 17, n. 6, pp. 1269, 2006. 
[43] Puccetti G., Rossi, M., Morini, G.L., Kähler C.J., Sensitivity to shear stress of nonencapsulated thermochromic liquid crystal (TLC) particles for microfluidic applications, Microfluid. Nanofluid., vol. 20, paper 19, pp. 1-7, 2016.

[44] Segura, R., Cierpka, C., Rossi, M., Joseph, S., Bunjes, H., Kähler, C.J., Non-encapsulated thermo liquid crystals for digital particle tracking thermography/velocimetry in microfluids. Microfluid. Nanofluid., vol. 14, n. 3-4, pp. 445-456, 2013.

[45] Segura, R., Rossi, M., Cierpka, C., Kähler, C.J., Simultaneous three-dimensional temperature and velocity field measurements using astigmatic imaging of non-encapsulated thermo-liquid crystals (TLC) particles, Lab Chip, vol. 15, pp. 660-663, 2015.

[46] Easley, C.J., Legendre, L.A., Roper, M.G., Wavering, T.A., Ferrance, J.P., Landers, J.P., Extrinsic Fabry- Perot Interferometry for Noncontact Temperature Control of NanoliterVolume Enzymatic Reactions in Glass Microchips, Anal. Chem., vol. 77, pp. 1038-1045, 2005.

[47] Seger-Sauli, U., Panayiotou, M., Schnydrig, S., Jordan, M., Renaud, P., Temperature measurements in microfluidic systems: Heat dissipation of negative dielectrophoresis barriers, Elecrophoresis, vol. 17, pp. 1115-1120, 1996.

[48] Kitamura, N., Hosoda, Y., Iwasaki, C., Ueno, K., Kim, H.B., Thermal phase transition of an aqueous poly ( $\mathrm{N}$-isopropylacrylamide) solution in a polymer microchannel-microheater chip, Langmuir, vol. 19, pp. 8484-8489, 2003.

[49] Lacey, M.E., Webb, A.G., Sweedler, J.V., Monitoring temperature changes in capillary electrophoresis with nanoliter-volume NMR thermometry, Anal. Chem., vol. 72, pp. 49914998, 2000.

[50] Lacey, M.E., Webb, A.G., Sweedler, J.V., On-line temperature monitoring in a capillary electrochromatography frit using microcoil NMR, Anal. Chem., vol. 74, pp. 4583-4587, 2002. 
[51] Kim, S.H., Noh, J., Jeon, M.K., Kim, K.W., Lee, L.P., Woo, S.I., Micro-Raman thermometry for measuring the temperature distribution inside the microchannel of a polymerase chain reaction chip, J. Micromech. Microeng., vol. 16, pp. 526-530, 2006.

[52] Patil, V.A., Narayanan, V., Spatially resolved temperature measurement in microchannels, Microfluid. Nanofluid., vol. 2, pp. 291-300, 2006.

[53] Astarita, T., Cardone, G., Carlomagno, G.M., Meola, C., A survey of infrared thermography for convective heat transfer measurements, Opt. Laser Technol., vol. 32, pp. 53-610, 2000.

[54] Carlomagno, G.M., de Luca, L., Infrared thermography in heat transfer, in Handbook of flow visualization, ed. Yang Wi, pp. 531-553,Hemisphere, Washington, D.C., 1989.

[55] Hallcrest, Handbook of Thermochromic Liquid Crystal Technology, 2014 (www.hallcrest.com/handbook_tlc_technology.pdf).

[56] Hohmann, C., Stephan, P., Microscale temperature measurement at an evaporating liquid meniscus, Exp. Therm. Fluid Sci., vol. 26, pp. 157-162, 2002.

[57] Muwanga, R., Hassan, I., Local heat transfer measurements in microchannels using liquid crystal thermography: methodology development and validation, . ASME J. Heat Transfer, vol. 128, pp. 617-626, 2006.

[58] Kenning, D.B.R., Konno, T., Wienecke, M., Investigation of boiling heat transfer by liquid crystal thermography, Exp. Therm. Fluid Sci., vol. 25, pp. 219-229, 2001.

[59] Liu, T.-L., Pan, C., Infrared thermography measurement of two-phase boiling flow heat transfer in a microchannel. App. Therm. Eng., vol. 94, pp. 568-578, 2016.

[60] Yoda, M., Kim, M., Studying interfacial transport with evanescent wave-based particle velocimetry and thermometry, Heat Transfer Engineering, vol. 34, n. 2-3, pp. 101-112, 2013. 
[61] Hsiek, S.S., Li, S.Y., Hsieh, Y.C., Noninvasive temperature measurements of RLIF and nPIT in DI water flow microchannels, Applied Thermal Eng., vol. 117, pp. 30-38, 2017.

[62] Kakuta, N., Fukuhara, Y., Kondo, K., Arimoto, H., Yamada, Y., Temperature imaging of water in a microchannel using thermal sensitivity of near-infrared absorption, Lab on a Chip, vol. 11, pp. 347-3486, 2011.

[63] Choi, S. B., Barron, R. F., and Warrington, R. O., Fluid Flow and Heat Transfer in Microtubes, Proc. of ASME DSC, Atlanta, GA, vol. 32, pp. 123-134, 1991.

[64] Yu, D., Warrington, R. O., Barron, R., and Ameel, T., An Experimental and Theoretical Investigation of Fluid Flow and Heat Transfer in Microtubes, Proc. of ASME/JSME Thermal Engineering Joint Conf., Maui, HI, vol. 1, pp. 523-530, 1995.

[65] Peng, X. F., and Peterson, G. P., Convective Heat Transfer and Flow Friction for Water Flow in Microchannel Structures, Int. J. Heat Mass Transfer, vol. 39, pp. 2599-2608, 1996.

[66] Wu, P., and Little, W. A., Measurement of the Heat Transfer Characteristics of Gas Flow in Fine Channel Heat Exchangers Used for Microminiature, Cryogenics, vol. 24, pp. 415-420, 1984.

[67] Piasecka, M., Strąk, K., Maciejewska, B., Calculations of Flow Boiling Heat Transfer in a Minichannel Based on Liquid Crystal and Infrared Thermography Data, Heat Transfer Engineering, vol. 38, n. 3, pp. 332-346, 2017.

[68] Frezzotti, A., Si Hadj Mohand, H., Barrot, C., Colin, S., Role of diffusion on molecular tagging velocimetry technique for rarefied gas flow analysis. Microfluid Nanofluid, vol. 19, n. 6, pp. 1335-1348, 2015.

[69] Si Hadj Mohand, H., Micro-vélocimétrie par marquage moléculaire adaptée aux écoulements gazeux confines, PhD Thesis, INSA Toulouse, 2015. 
[70] Hishida, K., Ichiyanagi, M., Kazoe, Y., Sato, Y., Combined laser-based measurements for micro-and nanoscale transport phenomena, Heat Transfer Engineering, vol. 35, n. 2, pp. 125$141,2014$. 
Gian Luca Morini

Table 1

List of the main scaling effects which affect the Nusselt number (from Morini and Yang [5])

\begin{tabular}{|c|c|c|c|}
\hline $\begin{array}{l}\text { Scaling } \\
\text { Effects }\end{array}$ & Liquid Gas & $\begin{array}{c}\text { Reference dimensionless } \\
\text { parameter }\end{array}$ & $\begin{array}{l}\text { Non } \\
\text { negligible } \\
\text { if: }\end{array}$ \\
\hline Entrance effects & $\mathbf{X}$ & $\mathrm{Gz}=\operatorname{Re} \operatorname{Pr}\left(\frac{\mathrm{D}_{\mathrm{h}}}{\mathrm{L}}\right)$ & $G z>10$ \\
\hline $\begin{array}{l}\text { Fluid axial } \\
\text { conduction }\end{array}$ & $\mathbf{X}$ & $\mathrm{Pe}=\operatorname{Re} \operatorname{Pr}$ & $P e<50$ \\
\hline $\begin{array}{c}\text { Wall-fluid } \\
\text { conjugate heat } \\
\text { transfer }\end{array}$ & $\mathbf{X}$ & $M=\frac{k_{w}}{k_{f}}\left(\frac{\Omega_{t o t}-\Omega}{\Gamma L}\right) \frac{1}{\operatorname{RePr}}$ & $M>0.01$ \\
\hline $\begin{array}{c}\text { Flow } \\
\text { compressibility }\end{array}$ & $\mathbf{X}$ & $M a_{\text {out }}=\frac{4 \dot{m}}{\pi D_{h}^{2}}\left(\frac{1}{p_{\text {out }}}\right) \sqrt{\frac{R T_{b, \text { out }}}{c_{p} / c_{v}}}$. & $M a_{\text {out }}>0.3$ \\
\hline $\begin{array}{l}\text { Viscous } \\
\text { dissipation }\end{array}$ & $\mathbf{X}$ & $B r=\frac{64 \mu}{q^{\prime \prime}{ }_{w} \Gamma}\left(\frac{\dot{m} R T_{b}}{\left(p_{\text {in }}+p_{\text {out }}\right) \pi D_{h}{ }^{2}}\right)^{2}$ & $B r>0.005$ \\
\hline Surface roughness & $\mathbf{X}$ & $e / d$ & $e / d>0.05$ \\
\hline Rarefaction & $\mathbf{X}$ & $K n=\frac{\zeta}{D_{h}}$ & $K n>0.001$ \\
\hline $\begin{array}{l}\text { Electro-osmotic } \\
\text { interactions }\end{array}$ & 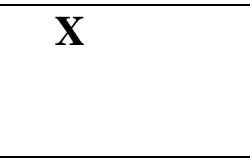 & $\mathrm{D}_{\mathrm{e}}=D_{h}\left(\frac{\varepsilon \kappa_{\mathrm{b}} \mathrm{T}}{2 \mathrm{n}_{0} \mathrm{Z}^{2} \mathrm{e}_{\mathrm{f}}^{2}}\right)^{-1 / 2}$ & $D_{e}<10$ \\
\hline $\begin{array}{l}\text { Temperature- } \\
\text { dependent } \\
\text { properties }\end{array}$ & $\mathbf{X}$ & $\begin{array}{c}T_{w} / T_{b} \text { (gas) } \\
\operatorname{Pr}_{w} / \operatorname{Pr} \text { (liquids) }\end{array}$ & \\
\hline
\end{tabular}




\section{Gian Luca Morini}

\section{Table 2}

Summary of the main experimental techniques useful for the analysis of micro-convection with the specification of the involved tracers.

\begin{tabular}{|c|c|c|c|}
\hline $\begin{array}{c}\text { Exp. } \\
\text { technique }\end{array}$ & Liquid Gas & Tracers & Measure \\
\hline LIF & $\mathbf{X}$ & $\begin{array}{c}\text { Rhodamine } B(R h B) \\
\text { Fluorescein }(F l) \\
\text { Kiton Red } \\
\text { Benzofurazan } \\
\end{array}$ & $\begin{array}{l}\text { Local Fluid } \\
\text { temperature }\end{array}$ \\
\hline DeLIF & $\mathbf{X}$ & $\begin{array}{c}\text { (RhB- } \\
\text { Fl)/(Rhodamine 110- } \\
\text { Sulforhodamine101) } \\
\text { Fluorescein27-RhB } \\
\text { Fluorescein- } \\
\text { Suforhodamine B }\end{array}$ & $\begin{array}{l}\text { Local Fluid } \\
\text { temperature }\end{array}$ \\
\hline EFT & $\mathbf{X}$ & $\begin{array}{c}\text { Fluorescein } \\
\text { Sulforhodamine B }\end{array}$ & $\begin{array}{c}\text { Near-wall } \\
\text { fluid } \\
\text { temperature }\end{array}$ \\
\hline MTT & $\mathbf{X}$ & $\begin{array}{l}\quad \text { NO molecules } \\
\text { Acetone molecules } \\
\text { Byacetyl molecules }\end{array}$ & $\begin{array}{l}\text { Local Fluid } \\
\text { temperature }\end{array}$ \\
\hline TLC & $\mathbf{X}$ & $\begin{array}{l}\text { Encapsulated or un- } \\
\text { encapsulated } \\
\text { particles }\end{array}$ & $\begin{array}{c}\text { Local Fluid } \\
\text { temperature } \\
\text { or local } \\
\text { wall } \\
\text { temperature }\end{array}$ \\
\hline NIRT & $\mathbf{X}$ & No tracers & $\begin{array}{c}\text { Near-wall } \\
\text { fluid } \\
\text { temperature }\end{array}$ \\
\hline IRT & $\mathbf{X}$ & No tracers & $\begin{array}{l}\text { Near-wall } \\
\text { fluid } \\
\text { temperature } \\
\text { or local } \\
\text { wall } \\
\text { temperature }\end{array}$ \\
\hline $\begin{array}{c}\text { PIV, PTV, } \\
\text { APTV }\end{array}$ & $\mathbf{X}$ & $\begin{array}{c}\text { Polystyrene } \\
\text { fluorescent particles } \\
\text { Liquid Cristals }\end{array}$ & $\begin{array}{l}\text { Local Fluid } \\
\text { velocity }\end{array}$ \\
\hline MVT & $\mathbf{X}$ & $\begin{array}{l}\quad \text { NO molecules } \\
\text { Acetone molecules } \\
\text { Byacetyl molecules }\end{array}$ & $\begin{array}{c}\text { Local Fluid } \\
\text { velocity }\end{array}$ \\
\hline
\end{tabular}




\section{Gian Luca Morini}

\section{Figure captions}

Figure 1 - Schematic of the apparatus adopted by Segura et al. [45] for simultaneous APTV and TLC measurements.: (1) rectangular copper microchannel $(200 \times 250 \mu \mathrm{m})$ sealed with a glass cover; $(2,3,4)$ Heating system based on a Peltier cell; (5) syringe pump; (6) RGB color camera; (7) inverted microscope; (8) objective lens; (9) linear polarizer; (10) achromatic quarter wave plate; (11) white light source.

Figure $2-2 \mathrm{D}$ velocity and temperature distribution of water in a copper microchannel $(200 \times 250$ $\mathrm{mm})$ with three sides heated $(\mathrm{Re}=0.04)$.

Figure 3 - Visualization of un-encapsulated TLC particles (Hallcrest UNR20C5W) added to water for: (a) shear rate at the wall equal to $100 \mathrm{~s}^{-1}$ (b) shear rate at the wall equal to $250 \mathrm{~s}^{-1}$. 
Gian Luca Morini

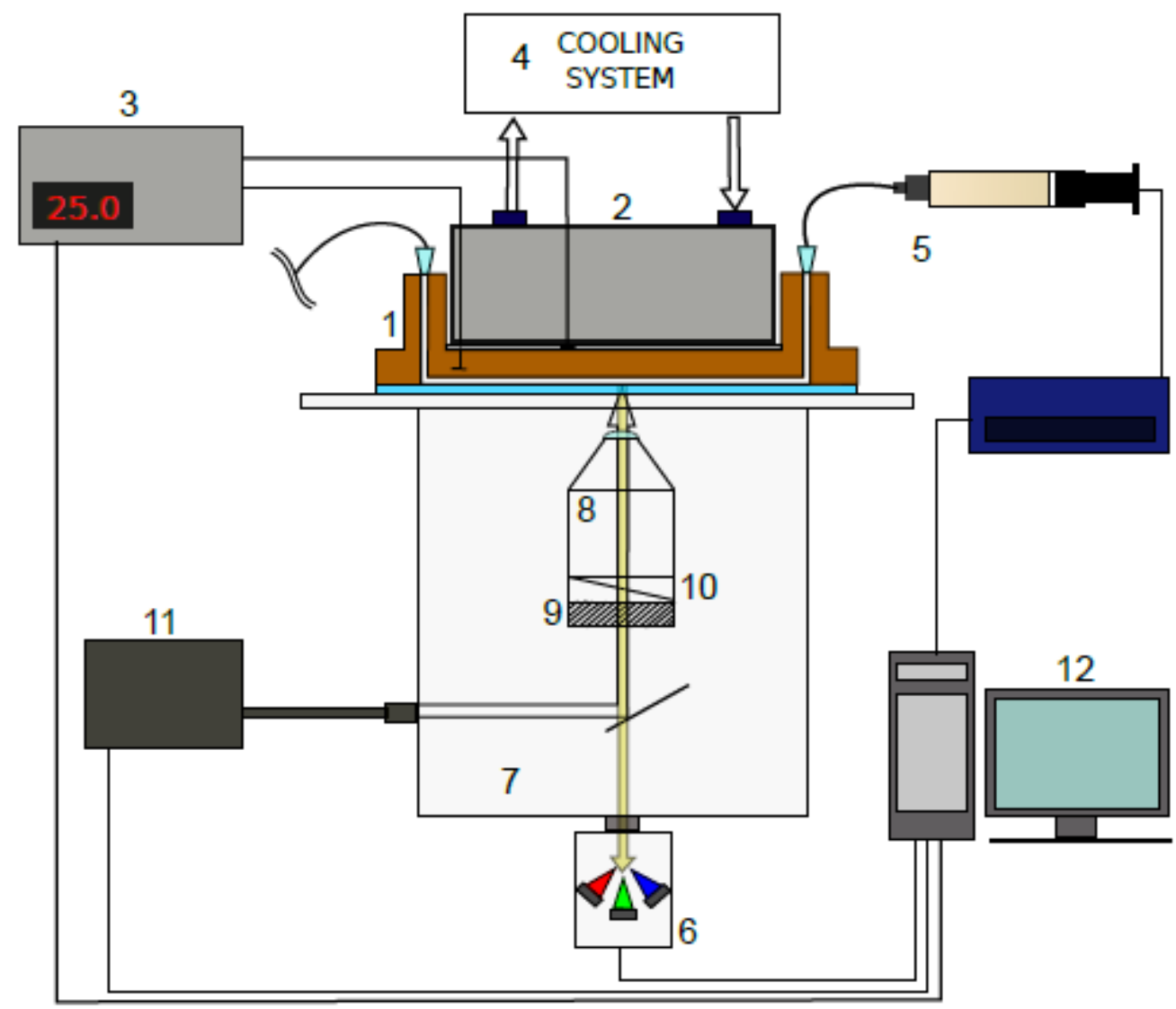

Figure 1 - Schematic of the apparatus adopted by Segura et al. [45] for simultaneous APTV and TLC measurements.: (1) rectangular copper microchannel $(200 \times 250 \mu \mathrm{m})$ sealed with a glass cover; $(2,3,4)$ Heating system based on a Peltier cell; (5) syringe pump; (6) RGB color camera; (7) inverted microscope; (8) objective lens; (9) linear polarizer; (10) achromatic quarter wave plate; (11) white light source. 


\section{Gian Luca Morini}

\section{Figure 2}

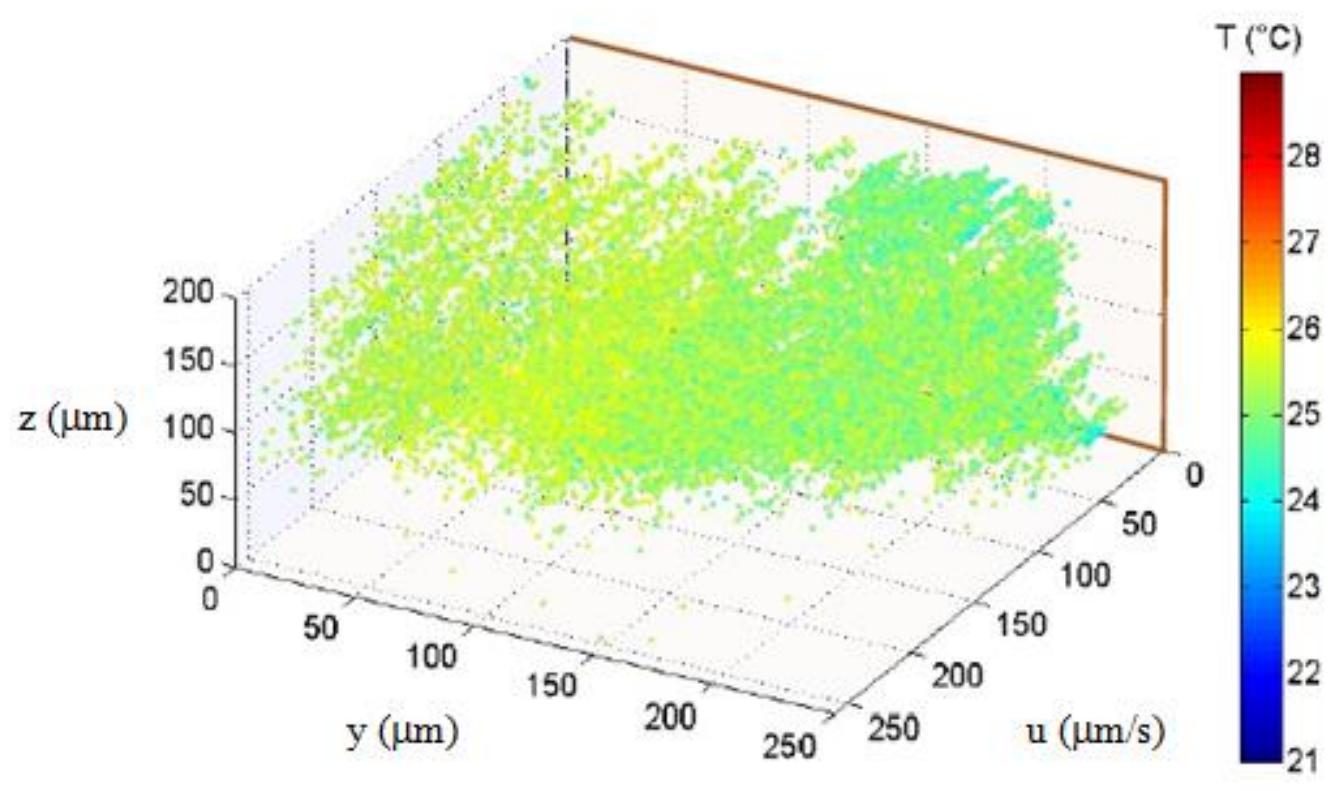

Figure $2-2 \mathrm{D}$ velocity and temperature distribution of water in a copper microchannel $(200 \times 250$ $\mathrm{mm})$ with three sides heated $(\mathrm{Re}=0.04)$. 
Gian Luca Morini

Figure 3
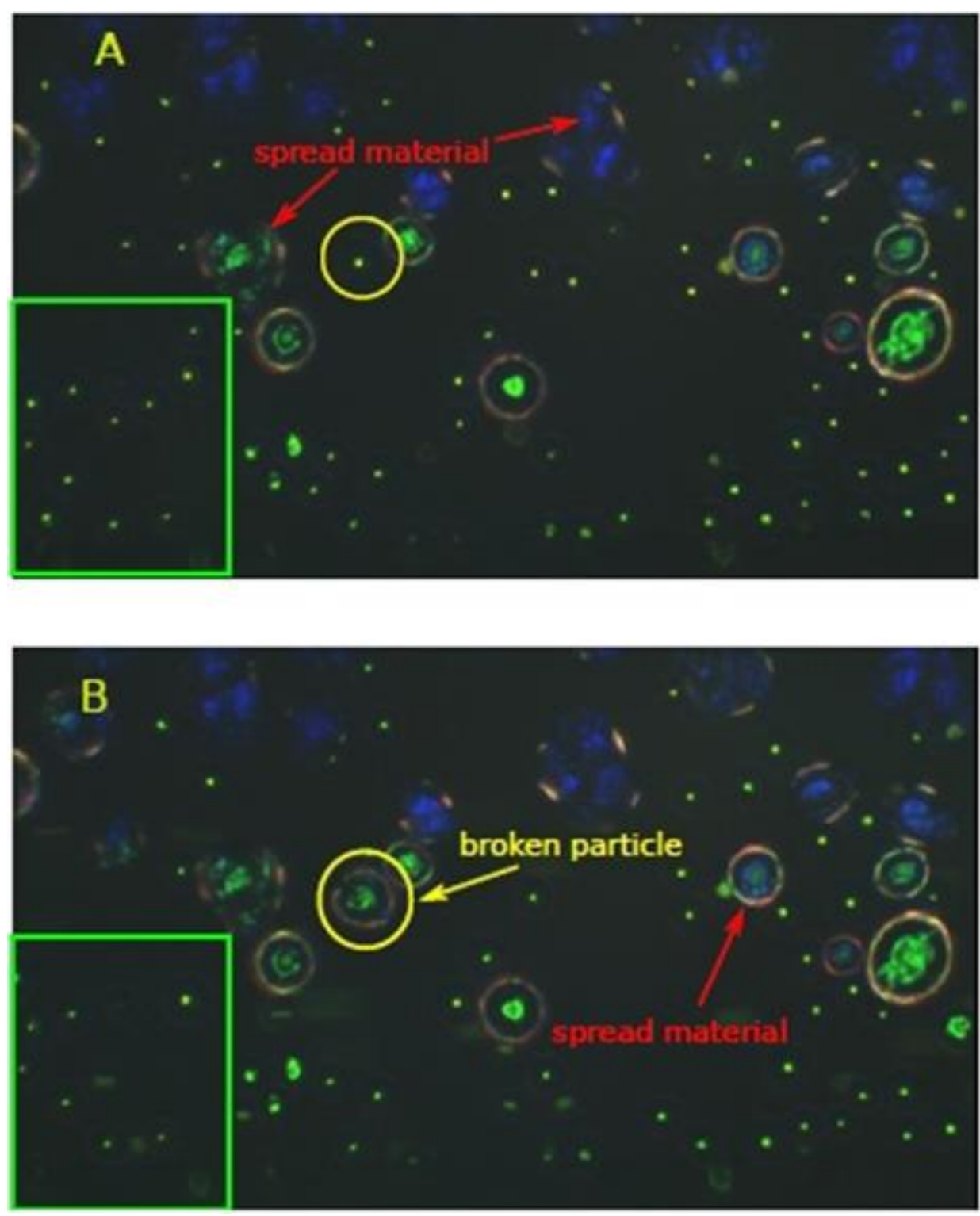

Figure 3 - Visualization of un-encapsulated TLC particles (Hallcrest UNR20C5W) added to water for: (a) shear rate at the wall equal to $100 \mathrm{~s}^{-1}$ (b) shear rate at the wall equal to $250 \mathrm{~s}^{-1}$. 


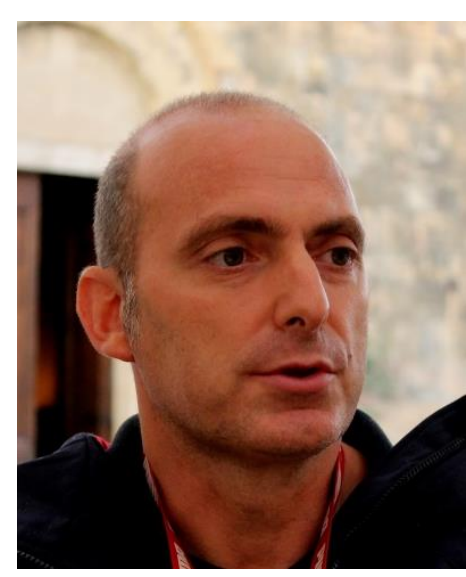

\section{Prof. Ing. Gian Luca Morini}

Gian Luca Morini is Professor of Applied Thermal Engineering at University of Bologna from 2002. Prof. Morini devoted his research activity to microscale heat transfer, forced convection in pipes, efficient HVAC systems and heat pumps design. He is author of about 200 technical papers appeared on the most important International Journals and Conferences related to Microfluidics, HVAC systems and Heat Transfer. Member of UIT, Italian delegate of the EUROTHERM Committee, member of the Scientific Council of International Center of Heat and Mass Transfer (ICHMT) and of the Assembly of the World Conference (AWC) on Experimental Heat Transfer, Fluid Mechanics, and Thermodynamics. 